\title{
Análise exploratória da adesão ao Sistema de Seleção Unificada (SiSU) pelas universidades federais por meio da Análise de Redes Sociais mapeadas a partir de dados abertos
}

\author{
Exploratory analysis of the adoption of a Unified Entrance Examination by Federal \\ Universities using Social Network Analysis based on open data
}

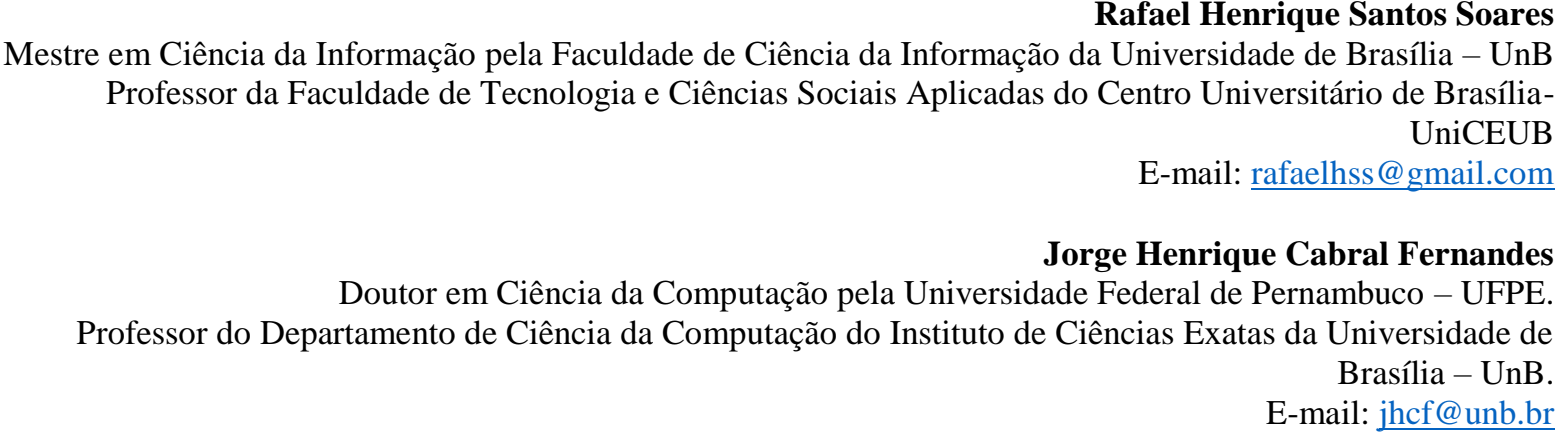

\section{Resumo}

Investiga a difusão da adesão ao SiSU entre universidades federais brasileiras utilizando Análise de Redes Sociais para estudo de redes mapeadas a partir do Diário Oficial da União. Propõe um método alternativo para coleta de dados para modelagem de redes sociais para estudos do fluxo de informação na Administração pública federal e apresenta uma metodologia de identificação de relacionamento entre órgãos baseada no processamento de texto. Utilizando as teorias da difusão de inovação em redes sociais, analisa o processo de adesão ao SiSU pelas universidades federais e mostra que a rede social das universidades e o fluxo de informações nela trafegado compõem a decisão de adesão ao novo sistema de seleção.

Palavras-chave: Análise de redes sociais. Coleta de dados. Dados abertos. Sistema de Seleção Unificado. Fluxos de informação. Comportamento Informacional

\begin{abstract}
Investigates the diffusion of innovation among Brazilian federal universities using Social Networking Analysis to study networks mapped from the Brazillian Official Gazette. Offers an alternative data collection method for modeling social networks for studies of information flow in the federal public Administration and presents a methodology identification of relationship based on text processing. Using the theories of innovation diffusion in social networks, analyzes the process of adoption of SiSU by federal and universities showing that the social network of universities and information flow influences their decision to join the new selection system.
\end{abstract}

Keywords: social network analysis. Data collection. Open data. Unified entrance examination. Information flow. Information Behavior.

InCID: R. Ci. Inf. e Doc., Ribeirão Preto, v. 7, n. 1, p. 181-200, mar./ago. 2016.

DOI: 10.11606/issn.2178-2075.v7i1p181-200 
Análise exploratória da adesão ao Sistema de Seleção Unificada (SiSU) pelas universidades federais por meio da Análise de Redes Sociais mapeadas a partir de dados abertos

\section{Introdução}

O fluxo de informações entre as universidades brasileiras é intenso e acontece espontaneamente, por meio de intercâmbio de docentes e discentes, cooperação em projetos, participações em congressos e conferências, e de forma induzida, como em programas governamentais como o "Ciência sem Fronteiras" ou os seminários e afins promovidos pelo Ministério da Educação. Esse fluxo de informações define uma rede de universidades federais dentro da qual são difundidas ideias, práticas, conceitos.

A intensidade dessa troca de informações entre cada par de universidades é determinante na influência que uma exerce sobre a outra e essa influência, por sua vez, pode se manifestar por meio de intercessões em publicações e achados científicos, projetos concluídos e abortados, decisões tomadas pela Direção dessas entidades, etc. Em última análise, a adoção ou não de inovações por parte de uma instituição se manifesta de diversas formas e cada ato público por ela executado tem o potencial de revelar um pouco desse processo.

O objetivo desse artigo é avaliar como a troca de informações entre universidades brasileiras, manifestada no Diário Oficial da União, pode ser usada para investigar o processo de difusão de inovações entre essas instituições. Busca-se compreender se é possível extrair informações do Diário Oficial da União que evidenciem a troca de informações entre cada Universidade e mapear a rede social de universidades brasileiras, então os fenômenos de difusão de inovações dentro dessa rede podem ser estudados usando Análise de redes sociais.

Um exemplo de inovação no ambiente das universidades federais, que inicialmente poderia ser adotada por qualquer uma delas com a mesma probabilidade, é o novo sistema de seleção de candidatos proposto pelo Governo Federal, o Sistema de Seleção Unificado - SiSU.

Esse artigo, portanto, investiga, sob o ponto de vista da Análise de Redes Sociais e do estudo dos fenômenos de difusão em redes, o processo de difusão da inovação: "adesão ao SiSU", dentro da rede social de universidades federais, e propõe que o relacionamento entre as universidades influencia no fluxo de informações entre elas e, consequentemente, constitui elemento importante no processo de decisão com relação à adesão ao SiSU.

Aqui se propõe que sejam utilizadas informações disponíveis no Diário Oficial da União para que sejam mapeadas as relações entre as universidades federais visando o mapeamento de redes que permitam o estudo da difusão.

InCID: R. Ci. Inf. e Doc., Ribeirão Preto, v. 7, n. 1, p. 181-200, mar./ago. 2016. 
Os fenômenos de difusão em redes sociais estão associados à transmissão de algo dentro da rede, de indivíduo para indivíduo. Pode ser uma ideia, uma nova tecnologia, um comportamento ou qualquer outro elemento que tenha por característica ser transmitido de elemento para elemento e no qual a configuração em rede tenha influência. Rogers (1995, p.15) define difusão em redes como “(...) o processo pelo qual uma inovação é comunicada por meio de certos canais ao longo do tempo entre os membros de um sistema social".

O SiSU é oferecido pelo Governo Federal às universidades brasileiras como alternativa ao vestibular tradicional desde 2009. Trata-se da utilização de infraestrutura tecnológica compartilhada entre as universidades e, principalmente, do mesmo exame (o Exame Nacional do Ensino Médio - ENEM) visando a seleção de candidatos a vagas em cursos de graduação. A adesão ao SiSU, embora encorajada pelo Ministério da Educação, é facultativa e as universidades devem avaliar a conveniência e oportunidade de adotar essa forma de seleção total ou parcialmente.

A adesão ao SiSU tem acontecido gradualmente ao longo dos anos e esse artigo visa investigar esse processo e como ele é influenciado pela troca de informações entre as universidades. Para tanto apresenta-se na seção 2 uma breve revisão da literatura que visa sustentar a utilização do Diário Oficial como base para mapeamento de redes sociais entre entidades federais. A seção seguinte discute as bases teóricas que sustentam a análise e as discussões sobre difusão de inovações em redes sociais. Na seção 4 apresenta-se a metodologia utilizada para o mapeamento das redes e para a extração das métricas utilizadas. A seção 5 discute os resultados obtidos e a seção 6 oferece comentários finais. 


\section{A Comunicação da Informação entre organizações públicas e sua manifestação no Diário Oficial da União}

Para entender como as publicações veiculadas em meios de comunicação oficial como o Diário Oficial da União podem ser estudadas como manifestações da comunicação entre organizações públicas é preciso investigar a dinâmica dessa comunicação dentro da Administração Pública. Para tanto, apresenta-se os conceitos de comunicação formal/informal de Le Coadic (2004, p. 35), a ideia de transição gradual entre informal e formal apresentada por Costa (2013) e o modelo de comunicação em espiral de Dance (1967, p. 374) para, finalmente, expor um esquema de comunicação da informação entre organizações públicas e sua manifestação no Diário Oficial da União.

Ao discutir a comunicação da informação Le Coadic (2004, p. 35) argumenta que o processo de comunicação pode ser desmembrado em dois outros: um processo escrito, formal, e um processo oral, informal. $\mathrm{O}$ autor ensina que o processo formal produz informações estáveis enquanto o processo informal entrega informações mais sujeitas a modificações e repetições. $\mathrm{O}$ autor defende que os processos informais antecedem os processos formais.

Analogamente à teoria apresentada por Le Coadic (2004, p. 35), podemos entender o processo de comunicação da informação que acontece nas organizações públicas brasileiras como um processo que também apresenta um componente formal e um componente informal. As decisões são tomadas internamente após análises conjunturais, discussões, estudos, e diversos outros processos suplementares que, dependendo do assunto a ser tratado, envolvem outros órgãos que compõem a administração. Algumas decisões de colaboração e de criação de grupos de trabalho ou implementação de projetos são tomadas após meses ou anos de negociações e intercâmbios informais de informação entre as organizações envolvidas.

A Tabela 1 mostra uma adaptação do quadro apresentado por Le Coadic (2004, p. 37) no qual o autor apresenta e confronta os elementos formais e informais da comunicação. Na tabela, inseriu-se duas colunas para oferecer exemplos de cada elemento proposto pelo autor no estudo da comunicação entre organizações públicas manifestado no Diário Oficial da União. 
Tabela 1 - Interseções dos elementos da comunicação e o processo de publicação no DOU

\begin{tabular}{|c|c|c|}
\hline & Formal & Informal \\
\hline $\begin{array}{l}\text { Citado por } \\
\text { Le Coadic }\end{array}$ & $\begin{array}{l}\text { Pública (audiência potencial } \\
\text { importante) }\end{array}$ & Privada (audiência restrita) \\
\hline $\begin{array}{l}\text { Interseção } \\
\text { com DOU }\end{array}$ & $\begin{array}{l}\text { Publicação em mídia impressa e na } \\
\text { internet }\end{array}$ & $\begin{array}{l}\text { Telefonemas, e-mails, reuniões, visitas } \\
\text { técnicas. }\end{array}$ \\
\hline $\begin{array}{l}\text { Citado por } \\
\text { Le Coadic }\end{array}$ & $\begin{array}{l}\text { Informação armazenada de forma } \\
\text { permanente }\end{array}$ & $\begin{array}{l}\text { Informação não armazenada, não } \\
\text { recuperável }\end{array}$ \\
\hline $\begin{array}{l}\text { Interseção } \\
\text { com DOU }\end{array}$ & $\begin{array}{l}\text { Arquivos e portal na internet com } \\
\text { pesquisa livre e irrestrita. }\end{array}$ & $\begin{array}{l}\text { Em alguns casos se encontra registros } \\
\text { precários como atas e relatórios, mas } \\
\text { geralmente não são estruturados. }\end{array}$ \\
\hline $\begin{array}{l}\text { Citado por } \\
\text { Le Coadic }\end{array}$ & Informação relativamente velha. & Informação recente \\
\hline $\begin{array}{l}\text { Interseção } \\
\text { com DOU }\end{array}$ & $\begin{array}{l}\text { Uma publicação no DOU é uma } \\
\text { comunicação de algo que já foi } \\
\text { decidido. }\end{array}$ & $\begin{array}{l}\text { A decisão está se construindo durante o } \\
\text { processo de comunicação. }\end{array}$ \\
\hline $\begin{array}{l}\text { Citado por } \\
\text { Le Coadic }\end{array}$ & Informação comprovada & Informação não comprovada. \\
\hline $\begin{array}{l}\text { Interseção } \\
\text { com DOU }\end{array}$ & $\begin{array}{l}\text { A publicação é ato necessário para } \\
\text { produção de efeitos, portanto goza de } \\
\text { veracidade. }\end{array}$ & $\begin{array}{l}\text { As informações têm caráter informal, e por } \\
\text { isso, menos compromisso com a } \\
\text { assertividade. }\end{array}$ \\
\hline $\begin{array}{l}\text { Citado por } \\
\text { Le Coadic }\end{array}$ & Disseminação uniforme. & Direção do fluxo escolida pelo produtor. \\
\hline $\begin{array}{l}\text { Interseção } \\
\text { com DOU }\end{array}$ & $\mathrm{O}$ acesso ao DOU é irrestrito. & $\begin{array}{l}\text { Somente os convidados a interagir têm } \\
\text { acesso à informação. }\end{array}$ \\
\hline $\begin{array}{l}\text { Citado por } \\
\text { Le Coadic }\end{array}$ & Redundância moderada. & Redundância muitas vezes importante. \\
\hline $\begin{array}{l}\text { Interseção } \\
\text { com DOU }\end{array}$ & $\begin{array}{l}\text { Uma publicação basta para produção } \\
\text { de efeitos. }\end{array}$ & $\begin{array}{l}\text { Temas complexos são discutidos e debatidos } \\
\text { por várias pessoas dentro dos órgãos, com o } \\
\text { envolvimento gradual de níveis hierárquicos } \\
\text { diferentes, justificando a redundância. }\end{array}$ \\
\hline $\begin{array}{l}\text { Citado por } \\
\text { Le Coadic }\end{array}$ & Ausência de interação direta. & Interação direta. \\
\hline $\begin{array}{l}\text { Interseção } \\
\text { com DOU }\end{array}$ & $\begin{array}{l}\text { A publicação é uma comunicação de } \\
\text { via única. }\end{array}$ & $\begin{array}{l}\text { Os agentes públicos interagem no processo } \\
\text { de comunicação acerca do tema. }\end{array}$ \\
\hline
\end{tabular}

Fonte: Adaptada do quadro apresentado por Le Coadic (2004, p. 36)

Costa (2013) oferece uma representação gráfica da classificação dos canais de comunicação organizacional. A figura 01 sintetiza essa relação e permite compreender o que podemos considerar como hierarquia dos canais quanto á forma.

Da análise da figura 01 percebemos que não há uma polaridade entre formal e informal, mas, um espectro que tem de um lado a comunicação estritamente formal e de outro a 
comunicação extremamente informal e, entre elas, uma infinidade de canais (e, portanto, de 'comunicações') que se distribuem gradualmente nessa classificação de acordo com seu 'grau de formalidade'.

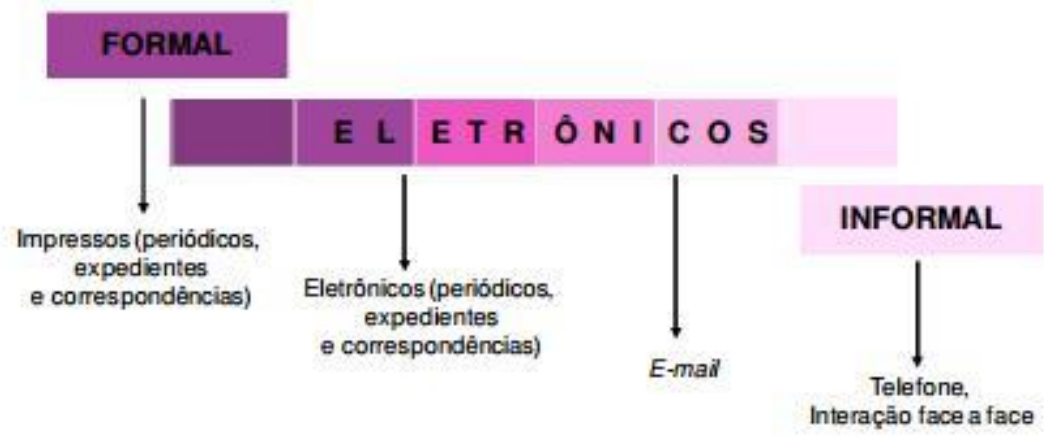

Figura 1- Classificação dos canais de comunicação para negócios Fonte: Costa, 2013

Dance (1967, p. 378), em seu trabalho, argumenta que a comunicação deve ser encarada como um processo contínuo e incremental. Ao criticar os modelos linear (por não representar feedback) e circular (por não representar o efeito que a troca de informações provoca nos indivíduos) o autor propõe um modelo helicoidal. $\mathrm{O}$ autor sugere que se use, em detrimento de linhas ou círculos, uma hélice, ou espiral, como figura geométrica básica para representação da comunicação humana. A espiral se adequa melhor, pois mostra a direção do fluxo da mensagem (como o linear), o movimento de retorno da retroalimentação (como o circular) e também o efeito incremental que a comunicação exerce sobre ela mesma, tornando-a maior e com mais informações e sentidos trafegados a cada interação.

McQuail e Windahl (1993) exaltam a característica dinâmica do modelo de Dance em comparação à "fotografia congelada" do processo de comunicação apresentada pelos demais modelos tradicionais. Os autores ressaltam, contudo, que Dance (1967) não formulou uma ferramenta para análises detalhadas, mas, ao invés disso, evidenciou uma característica que poderia ser facilmente negligenciada por estar ausente nos demais modelos.

A partir dessa perspectiva, é possível estudar a comunicação e mediação da informação entre organizações públicas por meio da análise das publicações no Diário Oficial da União, já que as publicações são uma projeção da comunicação prévia ocorrida entre os órgãos envolvidos.

Isto posto, o modelo apresentado na figura 2 visa demonstrar como a comunicação entre Organismos da Administração pública se comunicam no plano informal, como essa comunicação 
evolui até que se rompe a barreira entre espaço formal e informal e essa interação se manifesta por meio de publicações na imprensa oficial.

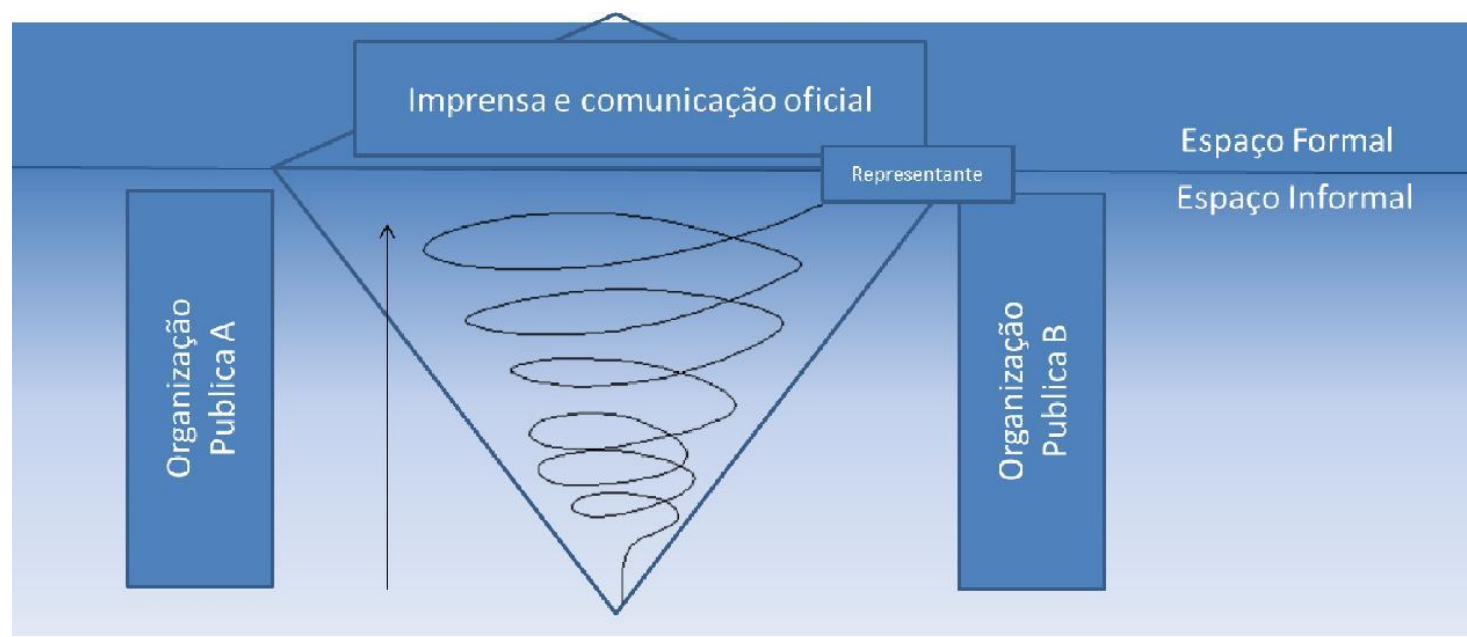

Figura 2 - Modelo de comunicação entre organizações públicas Fonte: Autores

Há um aspecto de mediação da informação envolvido no processo e desempenhado por parte da Organização que efetivamente operacionaliza a publicação. Ao elaborar o texto da portaria, esse elemento exerce o papel de representante na comunicação, tendo o poder de decidir qual parte do produto da comunicação entre os envolvidos será publicado e, eventualmente, omitindo informações.

Essa atuação provoca o efeito ilustrado pela forma de diamante ao fundo da imagem. Em analogia a um iceberg, a forma pretende ilustrar o fato de que há um volume de informação e uma comunicação muito mais intensa que acontece previamente à publicação veiculada no canal oficial de comunicação, que explicita apenas uma parcela do que realmente ocorreu previamente. Essa constatação permite expandir a análise e inferir que as manifestações detectadas em veículos como o Diário Oficial da União representem uma interação muito mais intensa e significativa que antecede essa publicação. 
Análise exploratória da adesão ao Sistema de Seleção Unificada (SiSU) pelas universidades federais por meio da Análise de Redes Sociais mapeadas a partir de dados abertos

\section{Fenômenos de difusão em redes sociais}

O conceito de difusão configura um processo social importante dentro da dinâmica estabelecida estruturalmente. Em uma rede o processo de comunicação é determinado pelo arranjo das conexões entre as pessoas. "Difusão é um caso especial de mediação que considera a dimensão tempo" (NOOY; MRVAR; BATAGELJ, 2005, p 161). Assim, as métricas de difusão tratam da maneira com que a informação (ou qualquer outro elemento 'transmissível') é transmitida dentro da rede, de um indivíduo ao outro, durante um intervalo de tempo.

A presença do aspecto social nos estudos sobre difusão se torna especialmente explícito na definição do que vem a ser Difusão. Rogers (1995, p. 17), em seu livro "Diffusion of Innovations", define o termo Difusão:

Difusão é o processo pelo qual uma inovação é comunicada por meio de certos canais ao longo do tempo entre os membros de um sistema social. [...] Difusão é um tipo de mudança social, definida como o processo pelo qual alterações ocorrem na estrutura e função de um sistema social. A essência do processo de difusão é a troca de informação pela qual um indivíduo comunica uma nova ideia a um ou muitos outros indivíduos.

Da definição de Rogers (1995) depreende-se que a difusão é um fenômeno típico das redes sociais e acontece tanto entre pessoas quanto entre organizações ("unidade de adoção" na definição citada), o que sugere a viabilidade de se estudar o fenômeno em redes sociais compostas de universidades federais, como sugere este trabalho. Com efeito, a definição do autor de 'sistema social' assevera que se trata de "um conjunto de unidades interconectadas e engajadas na solução de problemas de maneira conjunta, visando o atingimento de um objetivo comum" (ROGERS, 1995, p. 25).

O processo de difusão de inovações pode ser comparado a um processo de contaminação, semelhante ao alastramento de uma doença infecciosa. Dessa maneira Nooy, Mrvar e Batagelj (2005, p. 164) discutem o fenômeno da difusão ao apresentar o termo “contágio social” (social contagion) como sinônimo do fluxo de inovações em uma rede social. Os autores argumentam que, inicialmente, uma inovação é adotada por um grupo pequeno de pessoas que passa a crescer em ritmo relativamente rápido até que um grande número de pessoas adote a inovação ao mesmo tempo em que a taxa de crescimento desse grupo vai diminuindo. Por fim, o número de novos adotantes diminui drasticamente até que o processo de difusão se encerra. Trata-se de uma reação em cadeia na qual um elemento contamina seus vizinhos, que contaminam seus vizinhos e assim sucessivamente.

InCID: R. Ci. Inf. e Doc., Ribeirão Preto, v. 7, n. 1, p. 181-200, mar./ago. 2016. 
Esse comportamento, quando representado graficamente, apresenta como padrão uma curva em ' $\mathrm{S}$ '. A curva em ' $\mathrm{S}$ ' é um padrão em dados que representam reações em cadeia e "muitos estudos sobre difusão apresentam curvas de em formato de 'S'" (JACKSON, 2010, p. 5). A figura 03, extraída do trabalho de Nooy, Mrvar e Batagelj (2005, p. 165) representa uma curva em ' $\mathrm{S}$ ' genérica na qual as abcissas representam o tempo e as ordenadas indicam a proporção acumulada de indivíduos infectados (ou adotantes). Nela percebe-se que o processo tem início de forma contida até que a taxa de difusão acelera e, após algum tempo, volta a diminuir, tendendo a zero.

Os autores discutem o comportamento da curva em relação à posição estrutural do primeiro indivíduo exposto à inovação. Em fenômenos dessa natureza, indivíduos mais centrais são peças-chave no processo; podem ser o que Lazarsfeld (1944) chamou de "líderes de opinião”. Esses elementos, quando adotam a inovação, passam a participar como catalizadores do processo, fazendo com que aquela inovação atinja rapidamente um grande número de pessoas. Na figura 3, a linha preenchida representa o processo de difusão iniciado por um vértice central, bem localizado estruturalmente na rede. A linha tracejada indica o mesmo processo iniciado a partir de um vértice periférico. É nítida a percepção de que o processo iniciado pelo elemento periférico ocorre com menos rapidez, ou seja, a inovação leva mais tempo para atingir todos os elementos da rede. Isso mostra a importância dos grupos de "líderes de opinião" e as diferenças que podem ser observadas ao comparar processos de difusão ao mesmo tempo em que reafirma que, a despeito de como se inicia o processo, o mesmo formato da curva é esperado em situações onde o fenômeno ocorre.

Os autores argumentam, ainda, que o formato em ' $\mathrm{S}$ ' característico da curva é requisito para a identificação do fenômeno como um processo de difusão em rede:

\footnotetext{
Se encontrarmos uma curva de difusão que não apresenta o formato típico em $\mathrm{S}$, é pouco provável que as conexões da rede sejam importantes para o processo de difusão, e a difusão é propagada predominantemente por outras forças, como campanhas de mídia. (NOOY, MRVAR E BATAGELJ, 2005, p. 165)
}

A premissa do formato em 'S' foi utilizada por Christakis e Fowler (2010) em um estudo no qual, após a identificação dos elementos mais importantes estruturalmente em uma rede, foi possível prever o surgimento de epidemias baseando-se em uma projeção da curva. Mesmo sem mapear a rede por completo os autores foram capazes de extrair conclusões acerca da realidade fundamentando-se no fato de que o fenômeno de difusão em redes produz, necessariamente, uma curva com esse formato.

InCID: R. Ci. Inf. e Doc., Ribeirão Preto, v. 7, n. 1, p. 181-200, mar./ago. 2016. 


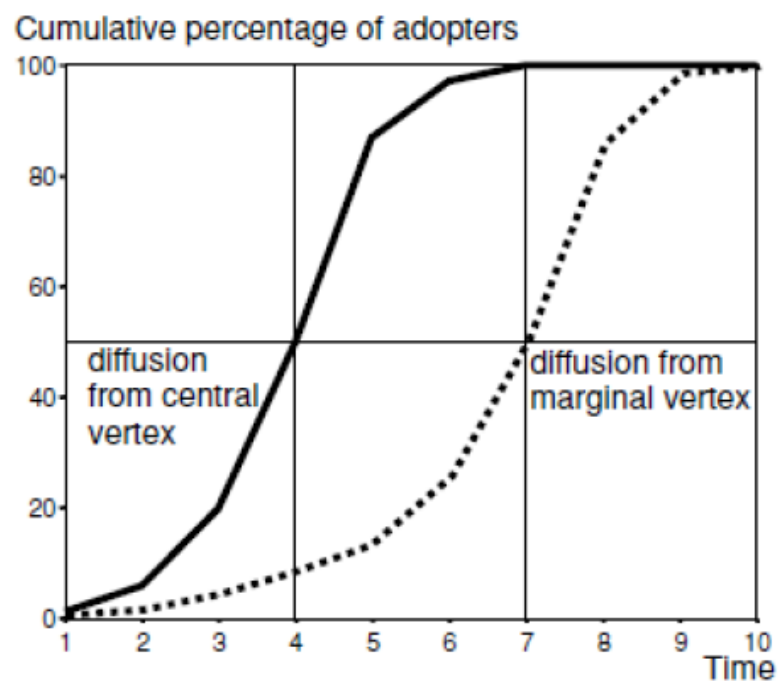

Figura 03 - Difusão acumulada a partir de um vértice central e um marginal.

Fonte: Nooy; Mrvar; Batagelj, 2005, p.165

\section{Metodologia}

A modelagem da rede de universidades federais usada para o desenvolvimento das análises foi feita com informações extraídas do Diário Oficial da União. O texto do Diário foi processado e a definição dos relacionamentos foi feita de forma análoga à proposta em trabalhos de infometria que utilizam a técnica chamada de co-word analisys.

A técnica do co-word, proposta por Courtial (1989), propõe uma abordagem baseada em grafos para a análise de textos e da relação estrutural entre as palavras e determina que se estabeleça uma borda entre dois termos (vértices) sempre que houver uma ocorrência de ambos no texto, com pouca distância entre eles. Estando os dois termos no mesmo excerto textual, observar-se-á uma ligação entre eles na rede social correspondente. A técnica se baseia no princípio de que termos mais relacionados tendem a aparecer mais próximos em textos. " $\mathrm{O}$ produto da análise co-word é, então, uma grande rede a qual expõe ligações entre conceitos problemas e ideias". (COURTIAL; LAW, 1989)

O processo é ilustrado na figura 4. Nela apresentam-se duas portarias distintas, publicadas por diferentes órgãos da Administração federal. Ambas citam Instituições de ensino federias e, seguindo a técnica $c o$-word, são identificadas e sua proximidade estrutural indicam uma ligação, materializada na sub rede exibida abaixo de cada portaria. O processo é repetido em cada portaria analisada e ao final do processo as sub redes encontradas são unificadas em 
uma única rede de instituições de ensino, como mostra, de forma simplificada, a parte de baixo da figura 4.

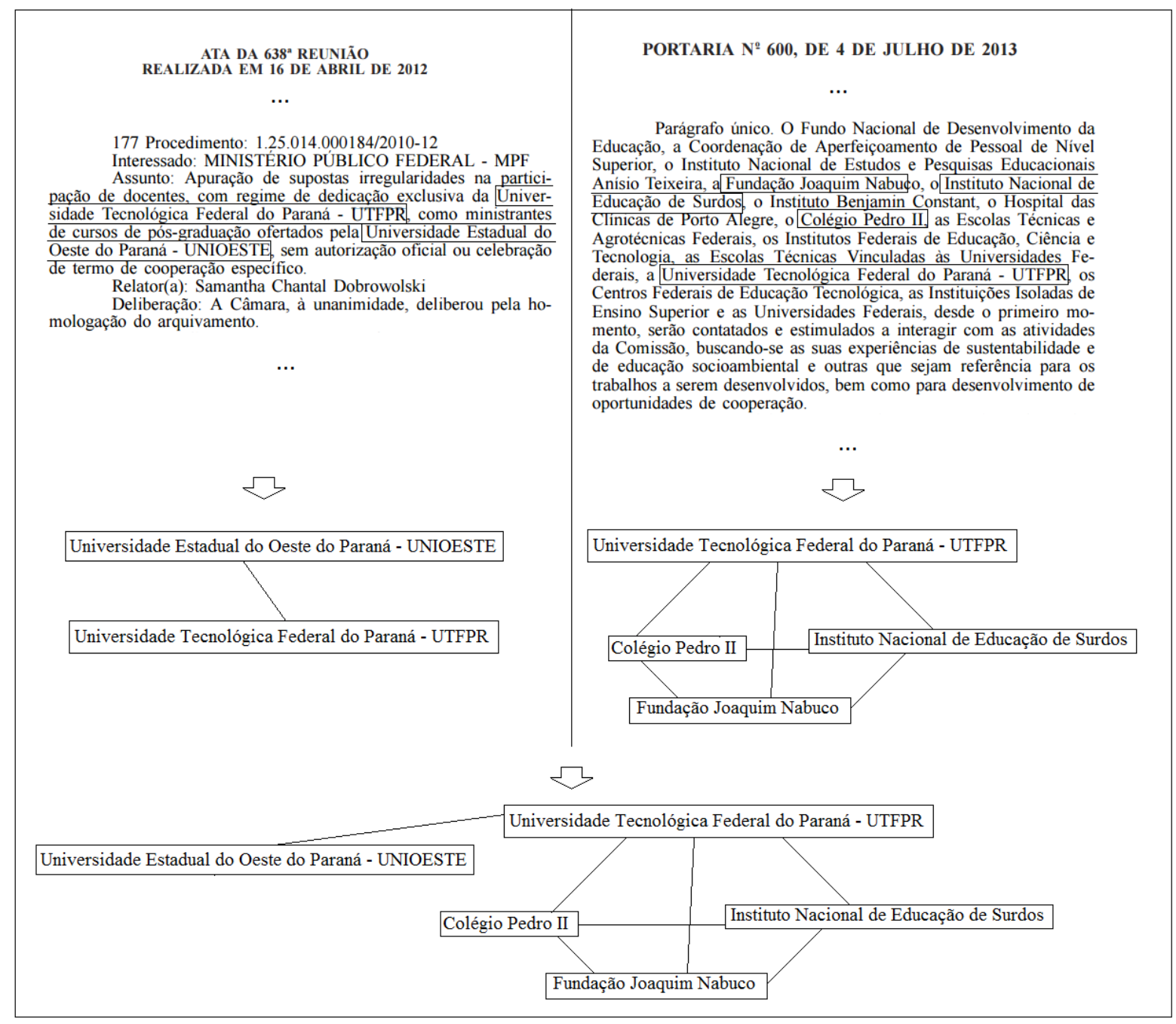

Figura 4 - Processo de mapeamento de redes a partir de publicações do Diário Oficial. Fonte: Autores

A coleta de dados envolveu o desenvolvimento de uma solução de software capaz de (1) buscar as páginas do Diário Oficial da União a serem processadas, (2) convertê-las de PDF para arquivo texto, (3) processar seu conteúdo identificando elementos chave: Instituições de ensino e Publicações (Portarias, leis, atos, etc.).

Foram coletados e processados dados referentes aos três jornais do Diário, no período compreendido entre 01/01/2012 e 01/04/2013.

A solução envolveu a utilização de componentes de processamento de linguagem natural, especificamente o GATE (CUNNINGHAM, et al., 2011), biblioteca especializada nessa tarefa que foi útil na tarefa computacional de detecção de nomes próprios e também na 
Análise exploratória da adesão ao Sistema de Seleção Unificada (SiSU) pelas universidades federais por meio da Análise de Redes Sociais mapeadas a partir de dados abertos

identificação dos padrões de apresentação textual que determinam as fronteiras entre uma publicação e outra.

Esse processamento produziu uma rede com 59 universidades federais e 6437 ligações entre elas.

Associada a essa rede foi criada uma partição - classificação única para cada vértice da rede - que representa o ano no qual a Instituição aderiu ao SiSU, caso isso tenha acontecido. Essa partição foi construída com base em uma tabela fornecida pelo Ministério da Educação após consulta baseada na lei de acesso informação. A tabela pode ser consultada no Anexo I deste trabalho.

De posse desses artefatos foi possível desenvolver a análise exploratória da rede de universidades federais.

A análise exploratória de redes sociais, da forma definida por Nooy, Mrvar e Batagelj (2005, p. 5), é uma técnica que permite que se estudem redes sociais visando a identificação e interpretação de padrões estruturais das relações sociais entre os indivíduos da rede sem uma rigidez metodológica significativa e sem hipóteses claras previamente estabelecidas.

A análise exploratória de redes sociais pressupõe que a estrutura ou padrão das ligações em uma rede social é significativa para os membros da rede e, portanto, para o pesquisador. Os autores argumentam que, ao conduzir esse tipo de análise exploratória, as hipóteses devem estar fundamentadas em teorias sociais e experiências de pesquisa anteriores, uma vez que não há envolvimento de técnicas como os testes de hipótese fornecidos pela Estatística.

Foram observados o posicionamento estrutural de cada elemento e sua classificação em relação à partição. A curva cumulativa de adesão e a quantidade de ligações entre cada nó também foram consideradas na análise, que combinou também outros elementos além das métricas da Análise de Redes sociais. O próximo item apresenta essa análise. 


\section{A Difusão da adesão ao SiSU pelas universidades federais}

Quando foi criado, inicialmente desvinculado do SiSU, o ENEM visava avaliar o ensino médio no País e não selecionar alunos. Assim, as primeiras ideias de utilizá-lo como instrumento de seleção não foram bem-vindas. "O Enem foi recebido, inicialmente, com descrédito por parte das universidades, e com reações contrárias, inclusive por parte dos estudantes". (WERLE, 2011, p. 1).

Entretanto, suas diretrizes foram adaptadas para esse fim e quando finalmente foi incorporado ao SiSU, a adesão inicial das universidades foi expressiva. Das 55 universidades federais da época, 26 aderiram ao sistema, atraídas principalmente pelas vantagens imediatas dessa nova modalidade de seleção, quais sejam, mitigação do ônus do vestibular (elaboração, segurança e logística), Excelência pedagógica (Elaboração acadêmica e Avaliação inclusiva) e Assistência estudantil (Participação no PNAEST e Financiamento federal) (FILHO; SILVA, 2013).

Algumas instabilidades ocorridas nos primeiros anos do sistema, contudo, retardaram o processo de difusão do novo método de seleção entre as universidades: “[...] Com a fraude, entretanto, denunciada na mídia, e a mudança de data de realização das provas para dezembro, muitas instituições de ensino retiraram sua adesão ao exame". (LIMA; PRADO; VIEIRA, 2011, p. 3).

Sobre o processo de adesão das universidades, o então ministro da educação Fernando Haddad se manifestou surpreso com a quantidade de universidades que o fizeram na primeira oportunidade (LIMA; PRADO; VIEIRA, 2011) e projetou que essa decisão seria tomada por todas as universidades em um curto prazo: “Quando planejamos a mudança, previmos um prazo de transição de três anos, ou seja, as universidades têm até 2011 para fazer com que o vestibular tradicional seja substituído pelo novo Enem”. (BRITO, 2009).

A previsão do ex-ministro, porém, não se concretizou, e, até o final de 2013, aproximadamente $30 \%$ das universidades ainda selecionavam seus alunos por meio de vestibular próprio.

Embora as decisões acerca da adoção de inovações sejam influenciadas por uma série de fatores, há indícios de que a adesão ao SISU seja um fenômeno de difusão e, portanto, tenha influência das estruturas das redes sociais das universidades Federais. 
Análise exploratória da adesão ao Sistema de Seleção Unificada (SiSU) pelas universidades federais por meio da Análise de Redes Sociais mapeadas a partir de dados abertos

Nesse sentido, destaca-se o posicionamento da Universidade Federal do Rio Grande do Sul - UFRGS - que, ao expor os motivos para a não adesão ao programa de seleção federal argumentou que há "necessidade de ampliar a discussão sobre o assunto. [...] apreciação de dados de outras universidades que adotaram o programa do MEC e o conhecimento de estudo nacional que está sendo desenvolvido pela Universidade Federal do Ceará sobre o tema, além de outras sugestões" (UNIVERSIDADE FEDERAL DO RIO GRANDE DO SUL, 2013 grifo nosso).

Da mesma forma, a Universidade Federal de Minas Gerais - UFMG -, que assinou o termo de adesão ao SiSU com efeito para a seleção dos entrantes em 2014, por meio de seu reitor, pronunciou-se nos seguintes termos: "Como reitor da UFMG, participo da Associação Nacional dos Dirigentes das Instituições Federais de Ensino Superior (Andifes), onde mantemos permanente contato e acompanhamos o que vem acontecendo em todas as instituições. Quase a totalidade das universidades federais já está no SiSU, e as poucas que ainda não o integraram plenamente, estão se decidindo a entrar" (ARAÚJO, 2013 - grifo nosso)

As partes destacadas na citação das notícias veiculadas nos portais da UFMG e da UFRGS mostram que essas universidades se comunicam com outras que possivelmente fazem parte da sua rede a fim de subsidiar o processo de decisão quanto à adesão ao SiSU. Trata-se aparentemente de uma situação semelhante à apresentada como a influência das relações sociais no processo de difusão de inovações.

A análise das métricas da rede social mapeada por meio dos textos do Diário Oficial também aponta nessa direção.

A figura 5 apresenta a imagem oferecida por Nooy, Mvar E Batagelj (2005, p.165) é apresentada novamente, dessa vez em comparação à curva da difusão acumulada da adesão ao SiSU na rede de universidades.

A curva de adesão ao SiSU apresenta um formato semelhante ao apresentado na figura proposta por Nooy, Mvar e Batagelj (2005, p. 165), aproximando-se do formato em ' $S$ ' característico da curva de difusão em redes sociais. Entretanto, o formato não é perfeitamente apresentado como um S, o que pode sugerir que outros fatores como pressões políticas tenham influência na decisão da instituição de ensino, e, portanto, embora influenciado pela rede de comunicação, a adesão ao SiSU seja resultado de um conjunto mais complexo de influências.

A rede de universidades que aderiram ao SiSU até o segundo semestre de 2013 é 
apresentada na figura 06 . Na imagem os vértices foram organizados em colunas de acordo com o semestre de adesão ao SiSU e foram excluídos os relacionamentos cujo número de ocorrências não superaram 20. Isso permitiu a visualização da rede de forma mais clara e considerando-se apenas os relacionamentos mais frequentes e assim supostamente mais relevantes.
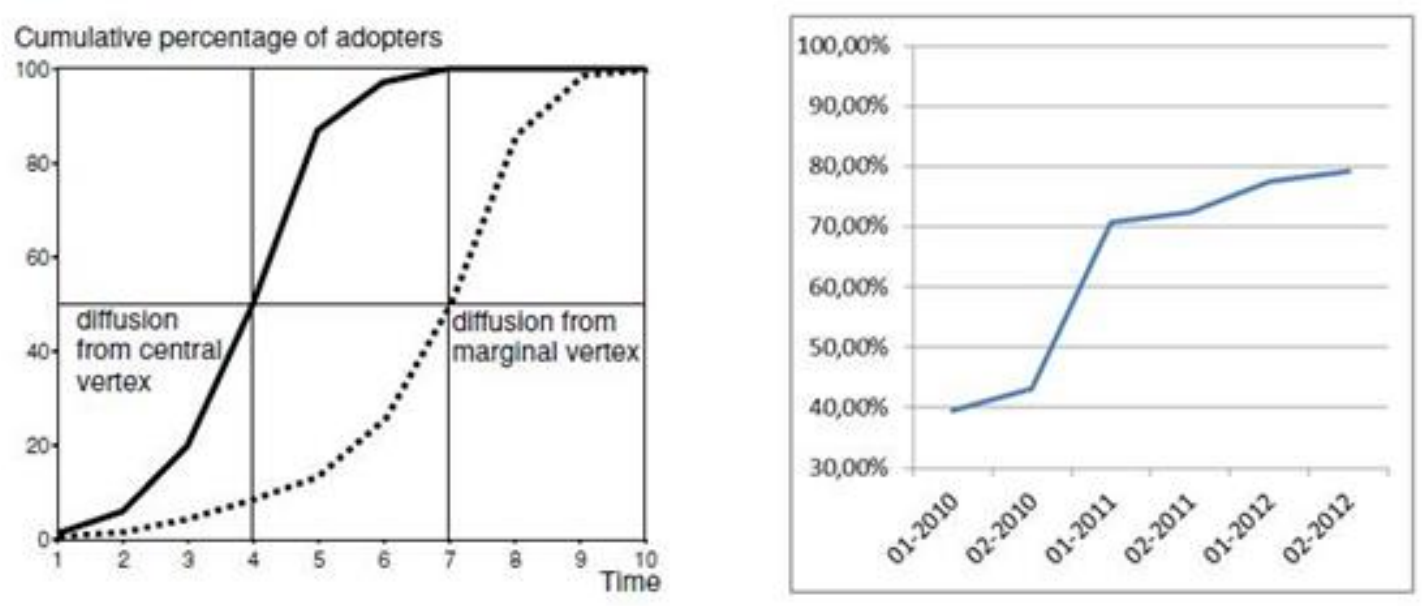

Figura 5 - À esquerda, difusão acumulada a partir de um vértice central e um marginal. À direita difusão acumulada da adesão ao SiSU na rede de universidades federais.

Fonte: Mvar; Nooy; Batagelj, 2005, p. 165 e dados da pesquisa

A figura 06 revela que, de forma geral, universidades cuja adesão ao SiSU se deu em períodos separados por mais de um ano não estão (fortemente) conectadas. Na rede apresentada é possível perceber, por exemplo, maior concentração de relacionamentos entre instituições cuja adesão se deu em 2010 (Amarelas, primeira coluna) e instituições que aderiram ao SiSU a partir do primeiro semestre de 2011 (Vermelhas, terceira coluna), e maior concentração entre as do primeiro semestre de 2011 e as que aderiram depois desse momento.

Há menos relacionamentos entre universidades que aderiram em 2010 e 2012 em diante, como se essa relação entre esses dois grupos (anterior a 2010 e posterior a 2012) estivesse sendo mediado pelo grupo que aderiu em 2011, o que pode indicar que o grupo das instituições que aderiram ao SiSU no primeiro semestre de 2011 o fizeram sob influência das que assinaram o termo de adesão em 2010 e, em seguida, influenciaram as que o fizeram no final de 2011. 
Análise exploratória da adesão ao Sistema de Seleção Unificada (SiSU) pelas universidades federais por meio da Análise de Redes Sociais mapeadas a partir de dados abertos

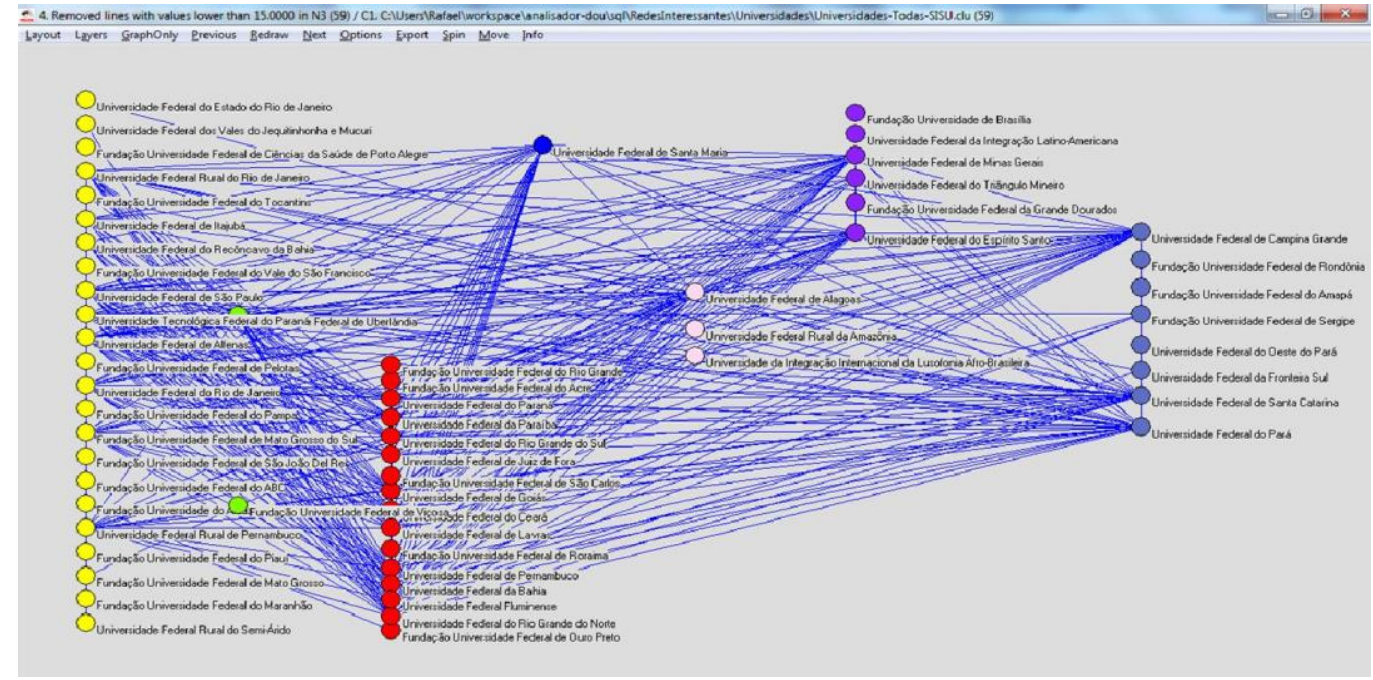

Figura 6 - Rede das universidades com linhas com mais de 20 ocorrências. Fonte: Autores

Embora o fenômeno da adesão ao SiSU por parte das instituições públicas de ensino certamente envolva muitos outros componentes não considerados na análise apresentada, os dados estudados sugerem que há algum nível de relação entre a rede de comunicação da informação estabelecida entre instituições públicas de ensino e a adoção de práticas como a adesão ao Sistema de Seleção Unificado.

\section{Conclusão}

Os fenômenos de difusão constituem um dos objetos de estudo mais importantes dentro da Análise de Redes Sociais. A composição em rede dos indivíduos parece ser bastante adequada para explicar eventos como epidemias, propagação de boatos, adoção de tecnologias entre outros muitos fenômenos cuja principal característica é a mudança de estado de um indivíduo por influência de seus relacionamentos com os demais indivíduos da rede.

A interação sistêmica observada entre organizações propicia o processo de difusão da informação e das inovações, que consiste na "troca de informação pela qual um indivíduo comunica uma nova ideia a um ou muitos indivíduos” (ROGERS. 1995, p. 17).

As redes mapeadas por meio de informações extraídas do DOU podem ajudar a investigar fenômenos de difusão uma vez que, conforme apresentado, refletem a proximidade entre organizações e pessoas com relação à intensidade da comunicação entre elas. Podemos, assim, assumir que em uma relação com fluxo de comunicação intenso exista maior probabilidade de influência e, portanto, no nível da rede, maior probabilidade da observação de 
fenômenos de difusão.

A rede de comunicação entre universidades revela como se dá a interação entre elas e quais são os grupos de instituições e as potenciais influências que umas podem exercer sobre as outras. A questão da seleção e admissão de novos alunos, por sua vez, afeta todas as universidades federais e, até 2010, não havia nenhuma grande diferença entre as soluções adotadas: vestibular tradicional. O advento do SiSU como alternativa ao vestibular foi instituído em 2010. Quando uma inovação (utilizando aqui os termos de Rogers (1995) é introduzida na rede de universidades, o processo de difusão pode vir a acontecer, emergindo figuras que o adotam na primeira oportunidade e, em seguida, influenciam os demais que o fazem com seus vizinhos sucessivamente.

A adesão ao SiSU é uma decisão complexa e influenciada por diversos fatores que vão de aspectos políticos a econômicos. Dentre os fatores, como exposto no capítulo 5, destacamse as dúvidas sobre a eficiência do sistema e as consequências que ele pode ter no funcionamento da instituição. Assim, como a maioria das decisões de adoção de inovações, a adesão ao SiSU parece ser um fenômeno de difusão que, em redes sociais, pode ser analisado através das técnicas de ARS.

Rogers (1995), oferece um modelo de "processo de decisão de inovação" que consiste de cinco estágios pelos quais o indivíduo passa quando exposto à inovação em um ambiente: (1) Conhecimento da inovação, (2) Persuasão, quando o indivíduo forma uma opinião sobre a inovação, (3) Decisão, quando o indivíduo age para adotar ou evitar a inovação, (4) Implementação, quando o indivíduo de fato usa a inovação e (5) Confirmação, quando o indivíduo procura reafirmar a decisão tomada.

O estado interno das universidades que ainda não aderiram ao SiSU pode variar de acordo com o proposto por Rogers, de acordo com o estágio da discussão acerca da adesão ao sistema. No capítulo 5 foram apresentadas declarações de reitores cujas universidades parecem estar na fase (2), ou seja, ainda estão formando opinião acerca da inovação. O reitor da UFMG argumentou que acompanha o resultado do programa em outras instituições por meio da participação na Associação Nacional dos Dirigentes das Instituições Federais de Ensino Superior, e o reitor da UFRGS expôs a necessidade de ampliar a discussão sobre o tema. Os dois exemplos mostram como as universidades citadas ainda estão formando opinião sobre a inovação, e reforça o aspecto da influência que as universidades que já aderiram exercem sobre as que ainda não o fizeram. A Universidade do Ceará, por sua vez, parece estar na fase (5), a 
Análise exploratória da adesão ao Sistema de Seleção Unificada (SiSU) pelas universidades federais por meio da Análise de Redes Sociais mapeadas a partir de dados abertos

fase de confirmação, na qual o indivíduo reafirma sua decisão, pois além de já ter adotado a inovação, está desenvolvendo estudos sobre o impacto do SiSU que tem grande potencial de influência sobre os demais, conforme apresentado.

Os métodos apresentados são uteis principalmente para identificar se o processo em análise é, de fato, um fenômeno de difusão. A partir da análise dos dados e de uma conclusão nesse sentido, é possível traçar estimativas com relação aos eventos futuros nesse contexto e tentar estimar se uma determinada política, como o SiSU, tende a se tornar um padrão ou se sua difusão plena entre os órgãos envolvidos demanda intervenções extras no sentido de atrair o interesse das organizações que ainda não a implementaram.

A identificação de elementos centrais dentro da rede também pode ser útil nesse sentido, pois, conforme discutido no capítulo 2, os fenômenos de difusão têm por característica um começo discreto e lento e sua aceleração se dá ao longo do tempo à medida que mais indivíduos são atingidos. Os elementos centrais, quando adotam uma inovação, tendem a catalisar esse processo devido à sua posição estrutural privilegiada. Assim, a identificação desses elementos nas redes é de grande interesse para o investigador de fenômenos de difusão.

Os métodos de análise de fenômenos de difusão são aqui apresentados de forma independente, mas é imprescindível que seus resultados sejam analisados dentro do contexto político que envolve a rede estudada. A adoção de uma determinada inovação, principalmente no ambiente da administração pública, está frequentemente sujeita a imposições legais e outras forças que não têm correspondência com a rede de comunicação entre organizações. Em espaços onde há algum grau de liberdade como o caso das universidades e SiSU, contudo, as teorias e técnicas apresentadas parecem ser úteis no entendimento do processo. 


\section{Referências}

ARAÚJO, A. R. UFMG adere ao Sisu em substituição ao concurso vestibular. Boletim, Belo Horizonte, ano 40, n. 1813, 25 mar. 2013. Acesso unificado. Disponível em:

<https://www.ufmg.br/boletim/bol1813/3.shtml >. Acesso em: 15 set. 2013.

BRITO, P. Ministro da Educação avalia adesão ao Enem. Boletim, Belo Horizonte, ano 35, n. 1660, 06 jun. 2009. Acesso unificado. Disponível em:

<https://www.ufmg.br/boletim/bol1660/6.shtml>. Acesso em: 15 set. 2013.

CHRISTAKIS, N. A.; FOWLER, J. H. Social network sensors for early detection of contagious outbreaks. PLoS ONE, v. 5, n. 9, set. 2010. Disponível em:

<http://dx.doi.org/10.1371\%2Fjournal.pone.0012948>. Acesso em: 10 jan. 2014.

COSTA, S. M. S. Comunicação para negócios: notas de aula da disciplina Fundamentos em Comunicação e Mediação da Informação. Programa de Pós-Graduação da Universidade de Brasília. 2013.

COURTIAL, J.; LAW, J. A co-word study of artificial intelligence. Social Studies of Science, v. 19, n. 2, p. 301-311, maio 1989. Disponível em:

<http://www.jstor.org/stable/pdfplus/285145.pdf?acceptTC=true>. Acesso em: $18 \mathrm{dez} .2013$

CUNNINGHAM, M. et al. Developing Language Processing Components with GATE Version8 (a User Guide). Sheffield: University of Sheffield Department of Computer Science. 2011. Disponível em: 〈http://gate.ac.uk/sale/tao/tao.pdf>. Acesso em: 05 maio 2013.

DANCE, F. Human communication theory: original essays. Michigan: Holt, Rinehart and Winston, 1967.

FILHO, F. S. S.; SILVA, C. A. P. Adesão ao SiSu: o que mudou para a UESPI?. In: FÓRUM NACIONAL DE REITORES, 53., 2013. Foz do Iguaçu. Anais... Foz do Iguaçu: Associação Brasileira dos Reitores das Universidades Estaduais e Municipais - ABRUEM, 2013.

JACKSON, M. Social and economic networks. Princeton: Princeton University Press, 2010.

LAZARSFELD, P. F. et al. The people's choice: how the voter makes up his mind in a presidential campaign. Columbia: Columbia University Press, 1944.

LE COADIC, Y. A ciência da informação. 2. ed. Brasília: Brinquet de Lemos, 2004.

LIMA, K. R. R; PRADO, F. H. S.; VIEIRA, R. B. Políticas públicas de "democratização" da educação superior no governo Lula: Enem, Prouni, Reuni. In: V ENCONTRO BRASILEIRO DE EDUCAÇÃO E MARXISMOMARXISMO, EDUCAÇÃO E EMANCIPAÇÃO HUMANA, 5., 2011, Florianópolis. Anais... Florianópolis, 2011.

MCQUAIL, D.; WINDHAL, S. Communication models for the study of mass communications. Londres: Longman. 1993 
Análise exploratória da adesão ao Sistema de Seleção Unificada (SiSU) pelas universidades federais por meio da Análise de Redes Sociais mapeadas a partir de dados abertos

NOOY, W.; MRVAR, A.; BATAGELJ, V. Exploratory network analysis with Pajek.

Cambridge: Cambridge University Press, 2005.

UNIVERSIDADE FEDERAL DO RIO GRANDE DO SUL. UFRGS decide não aderir ao SiSU para ingresso em 2014. 09 ago. 2013. Disponível em:

<http://www.ufrgs.br/ufrgs/noticias/ufrgs-decide-nao-aderir-ao-sisu-para-ingresso-em-2014>. Acesso em: 15 set. 2013

ROGERS, E. M. Diffusion of innovations. New York: Free Press, 1995.

WERLE, F. O. C. Políticas de avaliação em larga escala na educação básica: do controle de resultados à intervenção nos processos de operacionalização do ensino. Ensaio: Avaliação e Políticas Públicas em Educação, Rio de Janeiro, v. 19, n. 73, p. 769-792, 2011. 